\title{
DESIGNING THE FUTURE - SUSTAINABILITY, DIGITISATION AND EMPLOYMENT INSECURITY
}

\author{
Rob STARLING \\ OsloMet, Norway
}

\begin{abstract}
Humanity is changing the world. Unsustainable growth and progress push against fragile planetary boundaries. Automation threatens to make large numbers unemployable in the future. Digitisation alienates older generations and globalisation connects the world. Human interactions with technology and societal responses to its consequences will impact individuals, companies, governments and the future of humanity. How does society prepare for unpredictable future scenarios, and what role do designers have in this transition? Through research and interviews with experts from the tech industry, representatives in Oslo City Council and Norway's public welfare agency, future opportunities are explored. Designers and institutions can utilise sustainable, human-centred, service, and systemsoriented design methods to develop solutions to problems at different societal levels. If we are to succeed in creating a sustainable future for humanity, there is a need for significant societal change and quickly. Fortunately, we are learning faster than ever before, becoming increasingly aware of the challenges, share a common goal, and have access to the tools and methods that are needed to change the systems in within which we live.
\end{abstract}

Keywords: Design, automation, future of work, sustainability, system thinking

\section{INTRODUCTION: THE NON-LINEAR NATURE OF PROGRESS}

Technological innovation is increasingly changing the world. As human understanding increases, we discover the negative consequences of previous 'solutions' to problems. The industrial revolution powered by fossil fuels rocketed humanity to its current state. Only now, two hundred years later, are we beginning to realize the dire consequences of releasing millions of years of stored carbon into the finite carbon sinks of planet earth. Now we are faced with the seemingly impossible task of reducing carbon emissions to zero by 2050 or risking leaving behind an uninhabitable planet [1]. These are the parameters that designers must work within, with humanity proceeding along a knife-edge where every unsustainable action tip the scales towards calamity.

Within our complex and chaotic planetary systems, every act creating ripples of consequences best understood in hindsight. Accurately predicting future scenarios becomes problematic as exponentially increasing variables soon become impossible to calculate. Human progress has dragged in its wake an inverted curve of environmental degradation, damaging the fragile balances of nature that we are enmeshed within. The introduction of the 2019 Sustainable Development Goals by the United Nations, was aimed to raise awareness of the importance of sustainable design, circular economic models, and the limited time frames that we have as a species to work within [2]. Institutions leaning into this green wave of sustainability, present an opportunity for designers, businesses and institutes to push the boundaries of the sustainable design of products, services and systems.

Most things in life progress with linear growth patterns, with nature existing in a fragile balancing act where each change eventually finds a new equilibrium, the speed of human progress is not allowing natural systems to reach equilibrium with humanity. Ray Kurzweil's law of accelerating returns explains why the non-linear nature of technological innovation is hard to comprehend [3]. The rate of change is difficult to predict due to the $\mathrm{S}$ shape that progress follows, with rapid innovation being followed by a cooling-off period as we acclimatize to new technologies. The most recent wave of progress was the tech bubble of social media that we are becoming increasingly familiar with, and the next wave will likely be the artificial intelligence revolution [4]. 

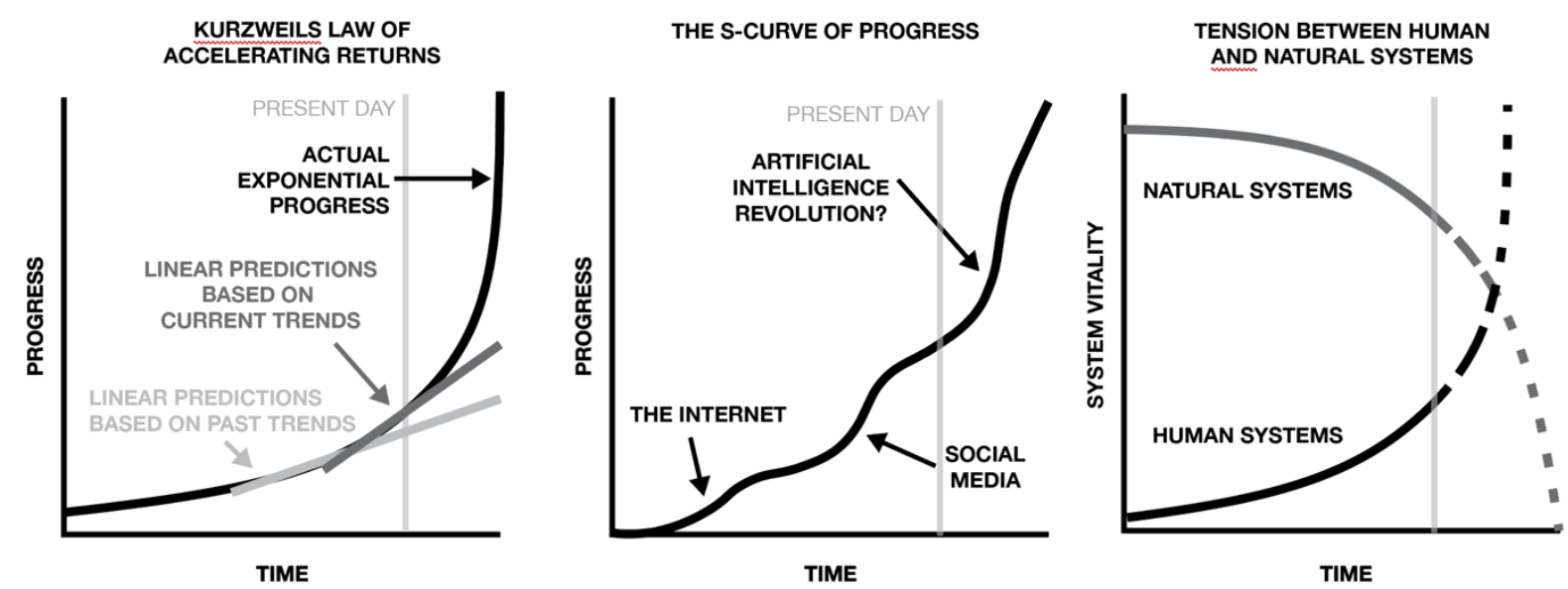

Figure 1. The difficulty in predicting progress and the tension between human and natural systems

\section{BACKGROUND, THE PARAMETERS OF PROGRESS}

"Design can broadly be defined as deliberate action aimed at turning existing living conditions into preferred ones" [5]. Creating sustainable products, services and systems that empower individuals and communities without damaging the planet is a difficult task. A thousand years ago, the Vikings left behind a legacy of a few pieces of metal, glass and ceramics, most of their possessions and infrastructure returning to natural systems. Our current society is increasingly creating mountains of unsorted garbage, crippling ecosystems and inhabiting sterile urban wastelands. Designers can play a role in the return towards balance with natural systems by creating products sustainably designed to fit a circular economy, functioning systems of resource recovery, services intended to liberate and empower people, and policies designed to enable governments and inter-governmental agencies to protect our fragile planet. We need to encourage the shift to first sustainable and then regenerative ways of living. We must make this transition deliberately. Donella Meadows explains in her book, the limits to growth, "When the present economy overshoots, it turns around too quickly and unexpectedly for people and enterprises to retrain, relocate, and readjust. A deliberate transition to sustainability would take place slowly enough, and with enough forewarning, to that people and businesses could find their places in the new economy" [6].

For humanity to exist in the long term, it needs to be in social, economic and environmental balance, neglect in any of these areas carries consequences. Kate Raworth explores the sustainable parameters as a 'doughnut' that society must balance all its systems within to thrive [7]. The field of design has evolved from impacting physical objects to working with the emotions and experiences of services, and now the designing of complex systems and policy. "The global economy has been transformed from a materialbased economy into a knowledge-based economy. Previously the main sources of wealth were material assets such as gold mines, wheat fields and oil wells. Today the main source of wealth is knowledge." [8]. Digital technologies make the world smaller, bringing news of previously distant events and experiences closer. The knowledge of a problem is necessary if one is to find a solution.

In a knowledge-based economy, education is power. Digital platforms share and spread knowledge, ideas and cultures globally. Learning has never been so easy to attain or share, forcing companies and educational institutions to rethink the way they work or risk obsolescence, this is the driving force of much of the work in which Sopra-Steria is engaged. Students entering the education system now will exit into a work environment where many of today's jobs no longer exist. Higher education qualifications lose their value as more people attain them and push non-academics to the fringes of the job market. In the design industry, the structures of companies are changing fast, and the methods and tools that designers utilise are under constant evaluation. Flexibility and the ability to continue learning once outside of academia is an increasingly important skill. Older generations are disadvantaged in a fast-paced, increasingly high-tech world, where skills can quickly become outdated. Perhaps that is why they are looking to the youth to solve these complex problems like climate change, the first "digital natives", the pessimistically labelled generation $\mathrm{Z}$. 

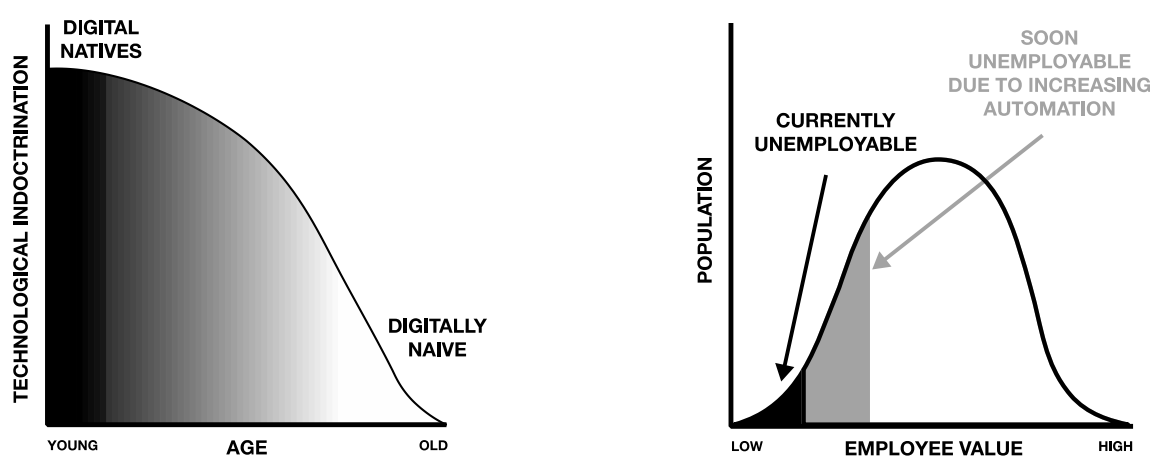

Figure 2. As technology alienates the elderly, automation makes more people unemployable

The industrial revolution replaced horse-drawn carts with cars and horses disappeared from everyday life. With self-driving vehicles predicted to hit the road within a few years, millions of people's skills will become obsolete [9]. What markets will they transition into in an autonomous world? Machine learning and AI are likely to impact many industries, where will these dispossessed people go? According to a study from the University of Oxford, looking at 702 different occupations in the USA, $47 \%$ of jobs are vulnerable to computerization [10]. Societies need to prepare for these changes.

Technological advancements allow staff in most professions to accomplish far more than was possible a generation ago. Wages and work hours, however, have not risen proportionately to this increased efficiency. Increased profits rarely make their way to workers in the form of higher salaries or shorter work weeks, many companies reduce staff or relocate to cheaper job markets, forcing people to adjust career paths. There have always been those that are unable to find a space in the labour market, now with automation removing the more manageable tasks this segment will increase. In the transition to automation, there is a real danger that benefits will increasingly go to the wealthy and negative impacts and job losses will fall on the poor, increasing inequality within countries and globally.

\section{METHODS}

In an interview with Tobias Studer Andersson, we explored the future of work from the perspective of Sopra-Steria, a company specializing in digitization consultation [11]. They help companies that are standing at the edge of a digital precipice to enter the modern age, taking them by the hand and guiding them into the digital realm. They match companies with the technology that best fits their needs through Sopra-Steria's networks and knowledge of the tech industry.

In interviews with three employees of Norway's public welfare agency (abbreviated to NAV) and Dagne Vaa, the head of its in-house design department [12], we explored the role of the designer and government's role in the future of employment. A prominent element of NAVs function is in getting people into or back into work. We explored the limitations within the system and possible future scenarios.

\section{FINDINGS}

\subsection{Interview with Sopra Steria}

The tech world is in constant flux, systems and software evolving and improving, and the range of digital platforms continually increasing, it requires agility to stay relevant. Sopra-Steria is seeing the benefit of design methodology and has invested heavily in Service and UX designers, increasing their design team from 2 to 60 between 2017-2019. The company focusses on creating enjoyable work experiences for its employees, nominated Norway's best place to work three years in a row.

Sopra-Steria encourages study while working, encouraging employees to boost their careers by taking courses in leadership and management and not discouraging people from leaving for other companies. They choose to frame off-boarding as sending ambassadors out into the world to strengthen the network of contacts from which the company can draw. The management style is hands-off, working out of the office but connected by digital platforms. Employees structure their days as they see fit, empowered through freedom and trusted to improve themselves and the company. 
Mentor programmes spread knowledge between those with experience and those with fresh skill sets. Employees are encouraged to share their unique perspectives, skills and expertise, in any way that the employee feels will benefit the company, from teaching yoga and mindfulness to holding classes in programming. This flexibility can lead to the emergence of creative community experiences within the company. Due to this focus on employee satisfaction, Sopra-Steria can choose from a large talent pool as their brand and reputation draw people to the company [11].

\subsection{Interviews with NAV employees}

In 2016 NAV hired its first designer and by March 2020 had 50 in-house designers. The focus is on improving and digitising the existing systems with the designers guiding the work to focus on the people using and working with the system. There is much room for improvement since every department in the country has an independent practice. The designers often find themselves following in the wake of the tech development team, where experts set the stage for projects and the tech department is tasked with implementing the concept, alongside the designers. Dagne stated the need for designers to be more involved in the decision-making process and lead projects from their inception and throughout their entire development [12].

NAV has a Data analysis department that looks for trends in data and forecasts possible scenarios and a department of knowledge that works on measuring scalability and efficiency within the services. The focus is on improving the current systems, and prioritisation of projects, not on exploring new ways of working or exploring possible future scenarios, having very little control over what can be experiment with, unlike the flexible tech world, being constrained by the checks and balances of bureaucracy and the mandates handed to it by politicians [12].

\section{DIscussion}

\subsection{Design methods}

There is a very different focus between design in the governmental and private sector, the motto 'work fast and break things' translates less well into bureaucratic systems, but the design techniques and methods used in both institutions are very similar. Both institutions are seeing the need for design competence and hiring in-house design teams, able to follow a project from start to finish, and enmeshing designers within multi-disciplinary teams. The ability to invest in designing enjoyable workplaces is easier to achieve in private companies, in public institutions, investment in worker satisfaction requires justification over more beneficial uses of government budgets.

Both agencies had a strong focus on human-centred design, allowing designers to keep the focus on the users of the products and services that they create. Service design combines quantitative and qualitative information, mixing hard data from research and technology with soft data from working with and understanding individuals and groups, this allows designers to build on the chaos of real life, rather than designing for hypothetical 'perfect' users. It is essential to create things that work in the way that people use them, and that can be understood. During the interview with Tobias from Sopra-Steria he explained that 'technology is like a bicycle, it can get you from A to B faster, but if you do not know how to use it, then it will slow you down' [11]. Systems-oriented design can allow designers to locate problem areas and leverage points and find ways to nudge or intercede in systems beneficially, and it is essential when designing within systems to consider possible negative ramifications. The designer has a responsibility to focus on liberating people, preserving life, encourage co-operation and championing the quest for knowledge and understanding.

Many of the projects that both agencies work on will have broad impacts throughout society and the labour market. Digitisation is a double-edged sword, improving people's experiences while disrupting the status quo for users and employees. A basic rule of capitalism is to increase revenues and decrease costs. Ideas that gain traction are often those with immediate economic benefits; charging for plastic bags and banning plastic straws save money and are easily adopted 'for the environment' without impacting profits. Supermarkets save on staff wages by automating tills, forcing customers to serve themselves. Profit focussed design is a race to the bottom where people and the environment pay the eventual costs. There is a real danger for the limitations of budgets to frame the digital shift that SopraSteria and NAV are involved with where money plays an important role. Web developer Gerry McGoven theorises that the issue stems from the culture of people entering IT because they dislike talking to people. He describes a deep-seated cultural aspect of traditional technology that sees people 
as the problem with the core purpose of technology to replace people when the goal ought to be to create a better and more efficient society [13]. Money plays a vital role in the success or failure of a design project and is something that designers should learn about in their studies.

\subsection{Mitigating employment disruption}

In preparation for the looming pressures on employment in the future governments around the world are preparing in different ways. Singapore is tackling this problem of job obsolescence with a system called 'second skilling' as Barbara Oakley explains in a TED article: "Every Singaporean 25 and older gets S\$500 (about US\$350) for skills training of their choice from the government through the Skills Future programme. It can pay for training in anything a person might want to learn, not just what their company needs them to know [14]. Second skilling could create a more resilient workforce in industries at high risk of automation, but where the transition may occur gradually, reducing the risk of system collapse. People become wary of entering industries at risk of becoming automated, and many will want to shift career for a safer future before automation takes over, this incentive system could help to bridge that unstable transition period.

Another approach is the universal basic income (UBI); the basic premise is that everyone should receive the bare minimum necessary to survive. The act of guaranteeing the basic human needs of food, shelter and clothing alleviates unnecessary tension, drama, stress and worry from people's lives at its source and provides essential security.

UBI is popular on both sides of the political spectrum as well as with tech companies for different reasons, if well designed it could strike a very positive balance. Tech companies are aiming to avoid the responsibility of their products forcing vast swathes of the populace out of employment; they would also prefer not to pay taxes on robots and support the idea of the government covering those costs. Conservatives would like to do away with inefficient government systems and the middlemen of bureaucracy and instead spend money where it is most needed. Liberals would like to increase equality and reduce the gap between rich and poor, increase the transparency of wealth distribution and tax people equivalently to their wealth. The idea is not to tax hard-working people but to tax rentiers that make money without contributing anything to society and redistributing hoarded wealth more equitably. The funding of a UBI could come from taxes on robots and automation, financial transactions, capital, land value and carbon emissions [15].

\section{CONCLUSIONS}

The systems that we design and accept will eventually be the ones that we live in, so we ought to make sure that they are good for us. There is always the risk of using design for nefarious goals (unintentionally or not), Hugo Boss's designs for the Nazi uniform and the eye-catching graphic design of the swastika certainly played a role in forming our past.

Legacies of past cultures litter our collective experiences. It could be that the advances that we have experienced in the last couple of hundred years have already locked in negative consequences that are irreversibly fatal for our species, but if there is a chance that we can solve the problems that threaten our future, then that ought to be our focus as designers. As far as we are aware, we are the only self-conscious creatures in our universe, perhaps because intelligence rarely advances faster than the consequences of its thoughtless early actions. If we design systems that empower the individual, then perhaps society is headed to becoming a leisure economy. With a strong welfare state and sensible government policy, some form of universal basic income could free people from work for the sake of it [16]. If we can share the benefits of technological progress and use automation to benefit people instead of enslaving them, then we could be headed towards a new renaissance of art, literature and self-expression. Within our current systems, it is difficult to imagine a world without work, a life without the struggle to survive, where everyone is worthy of a place in society no matter how much or how little they can contribute. Breakthroughs in society have tended to be driven by people liberated from drudgery. Philosophy arose when the exploitation of slave labour enabled the ancient Greeks to stop and think. The burning of dinosaurs powered the industrial revolution and the destructive expansion of empires. Our modern service economy is made possible by automation, environmental degradation and the exploitation of cheap labour overseas. The next era of human innovation could develop fuelled by clean, renewable energy systems with AI and machines doing the boring, repetitive, dangerous jobs, cheaper, more efficiently and better than humans ever could, freeing us to work on the more critical tasks of solving complex problems like; inequality, climate change and existential risks, working to unite humanity and 
expand the realm of human influence into space and eventually spreading consciousness throughout the stars.

In an increasingly complex world, there is an ever-increasing number of opportunities for designers to turn existing systems into preferred ones. The decisions that we make in designing products, services, systems, and influencing behaviour when compounded will impact the trajectory of humanity. More designers are entering the industry than ever before, and the understanding of the benefits of design thinking and methods is increasingly permeating society. We are all responsible for designing the future. If we are going to thrive as a species, we must teach people to design responsibly, sustainably and holistically.

\section{REFERENCES}

[1] United Nations (2018) Global warming of $1.5^{\circ} \mathrm{C}$ An IPCC Special Report on the impacts of global warming of $1.5^{\circ} \mathrm{C}$ above pre-industrial levels Available: https://www.ipcc.ch/site/assets/uploads/sites/2/2019/06/SR15_Full_Report_High_Res.pdf

[2] Nations, U. (2019). The Sustainable Development Goals Report. Available: https://unstats.un.org/sdgs/report/2019/The-Sustainable-Development-Goals-Report-2019.pdf

[3] Kurzweil, R. (2001). The Law of Accelerating Returns. Available: https://www.kurzweilai.net/the-law-of-accelerating-returns

[4] Urban, T. (2015). The AI Revolution: The Road to Superintelligence. Available: https://waitbutwhy.com/2015/01/artificial-intelligence-revolution-1.html

[5] Simon, H. A. (1982). The sciences of the artificial (2nd ed ed.). Cambridge, Mass: MIT Press.

[6] Donella H. Meadows, D. L. M., Jørgen Randers. (2004). The Limits to Growth: The 30-Year Update. Chelsea Green Publishing Company

[7] Raworth, K. (2017). Doughnut Economics. Vermont: Chelsea green publishing.

[8] Harari, Y. N. (2016). Homo Deus: A Brief History of Tomorrow. Vintage books, England.

[9] Kurzgesagt. (2017). The Rise of the Machines - Why Automation is Different this Time. Available: https://www.youtube.com/watch?v=WSKi8HfcxEk

[10] Carl Benedikt Frey, Michael A. Osborne. (2017). The future of employment: How susceptible are jobs to computerisation? Technological Forecasting \& Social Change (2017) Available: https://www.sciencedirect.com/science/article/pii/S0040162516302244

[11] Studer Andersson, T, Head of Scale-up Sopra Steria, Interview, October 2019

[12] D, Vaa, Head of design NAV, Interview, March 2020.

[13] Dalen, T. Sundby, I. Dekker, M (Producers). (2020). International Design in Government Conference 2019 [Podcast]. Available: https://podcasts.apple.com/no/podcast/internationaldesign-in-government-conference-2019/id1492122999? $1=1000459982462$

[14] Oakley, B. (2018). Could Singapore hold the secret to preparing workers for an uncertain future? Available: https://ideas.ted.com/could-singapore-hold-the-secret-to-preparing-workersfor-an-uncertain-future/

[15] World Economic Forum. (2019, 10. Oct) A Basic Income for All: Dream or Delusion? [Video clip] Available: https://m.youtube.com/watch?v=7rL6gJkdlNU

[16] Straubhaar, T. (2017). On the Economics of a Universal Basic Income. Available: https://archive.intereconomics.eu/year/2017/2/on-the-economics-of-a-universal-basic-income/ 